\title{
Endemik Anadolu Sığla Ağacı (Liquidambar orientalis Mill. ) Bitki Ekstraktlarının Bazı Bitki Patojeni Funguslara Karşı Antifungal Etkilerinin Belirlenmesi
}

\author{
Determination of Antifungal Effects of Endemic Anatolia Siğla Tree (Liquidambar orientalis \\ Mill.) Plant Extracts against Some Plant Pathogenic Fungi
}

\author{
Abdurrahman ONARAN* \\ Gaziosmanpaşa Üniversitesi, Ziraat Fakültesi, Bitki Koruma Bölümü, 60250, Tokat
}

• Geliş tarihi / Received: 06.06.2017 • Düzeltilerek geliş tarihi / Received in revised form: 02.01.2018 • Kabul tarihi / Accepted: 04.01.2018

\begin{abstract}
Öz
Geçmişten günümüze kadar, bitkilerden elde edilen doğal antifungal maddeler alternatif mücadele yöntemi olarak kullanılmaktadır. Bu çalışmada, ülkemizde endemik olarak yetişen Liquidambar orientalis Mill. bitkisinden elde edilen reçine ve yaprak methanol ekstraktının antifungal etkileri araştırılmıştır. Çalışmamızda, hıyar ve elma bitkilerinde sorun olan fungal hastalık etmenleri Fusarium oxysporum f.sp. cucumerinum (FOC) ve Monilinia fructigena'ya karşı agar petri metodu kullanılarak farklı bitki ekstraktlarının farklı konsantrasyonlardaki antifungal etkinlikleri araştırılmıştır. Çalışmalarda bitki ekstraktlarının 0 (negatif kontrol), 5, 10 ve $20 \mathrm{mg} / \mathrm{ml}$ konsantrasyonları kullanılmış ve elde edilen veriler sonucunda, miselyum gelişim engellemesi $(\mathrm{MGE})$ ve Letal doz $\left(\mathrm{LD}_{50-90}\right)$ değerleri belirlenmiştir. Ekstraktların fungal etmenlere karşı kullanılan her konsantrasyonunda antifungal aktivite göstermiştir. Konsantrasyon miktarı artıkça MGE değerlerinin (\%) arttığı belirlenmiştir. L. orientalis reçine ekstraktı için en yüksek MGE oranı, M. fructigena'da $\% 100$, FOC'da ise $\% 74$ olarak hesaplanmıştır. Bu değerlerin, L. orientalis yaprak ekstraktı uygulamasında ise M. fructigena'da $\% 66$ ve $F O C$ 'da $\% 51$ olarak belirlenmiştir. $\mathrm{LD}_{50}$ değerleri reçine ekstraktında $\mathrm{M}$. fructigena için 7.32 $\mathrm{mg} / \mathrm{ml}$ ve FOC için $4.42 \mathrm{mg} / \mathrm{ml}$, yaprak ekstraktında da M. fructigena için $16.98 \mathrm{mg} / \mathrm{ml}$ ve FOC için $7.65 \mathrm{mg} / \mathrm{ml}$ olarak belirlenmiştir. $L D_{90}$ değerleri ise reçine ekstraktında $\mathrm{M}$. fructigena için $7.68 \mathrm{mg} / \mathrm{ml}$ ve FOC için $51.48 \mathrm{mg} / \mathrm{ml}$ arasında, yaprak ekstraktında ise M. fructigena için $121.91 \mathrm{mg} / \mathrm{ml}$ ve FOC için $364.59 \mathrm{mg} / \mathrm{ml}$ olarak belirlenmiştir. Bu sonuçlara göre, test organizmalarına karşı reçine ekstraktı, yaprak ekstraktından daha etkili bulunmuştur.
\end{abstract}

Anahtar kelimeler: Antifungal Aktivite, Bitki Ekstrakt1, Liquidambar orientalis, Fusarium oxysporum f.sp. cucumerinum, Monilinia fructigena

\begin{abstract}
Natural antifungal substances obtained from plants are used as an alternative method of struggle from past to present day. In this study, the antifungal effects of different concentrations of methanol extract obtained from resin and leaves of Liquidambar orientalis Mill. plant, endemically grown in Turkey, was investigated by using agar plate method against fungal disease agents Fusarium oxysporum $f$. sp. cucumerinum (FOC) and Monilinia fructigena plant pathogens causing damage cucumber and apple plants, respectively were used. Mycelial growth inhibition (MGI) and lethal doses $\left(L D_{50-90}\right)$ were obtained by using concentrations of plant extarcts at 0 (negative control), 5,10 and 20 $\mathrm{mg} / \mathrm{ml}$. Plant extract showed antifungal effects at the all concentrations used. MGI (\%) values increased as the amount of concentration increased. Thus, the highest MGI ratio for L. orientalis resin is calculated 100\% against M. fructigena and $74 \%$ for FOC. These values were $66 \%$ for M. fructigena and 51\% for FOC for L. orientalis leaf extract. In addition, $L D_{50}$ values were $7.32 \mathrm{mg} / \mathrm{ml}$ for M. fructigena, $4.42 \mathrm{mg} / \mathrm{ml}$ for FOC in case of resin extract and $16.98 \mathrm{mg} / \mathrm{ml}$ for M. fructigena, $7.65 \mathrm{mg} / \mathrm{ml}$ for FOC in case of leaf extract. LD 90 values were found between $7.68 \mathrm{mg} / \mathrm{ml} \mathrm{for} \mathrm{M.}$ fructigena to $51.48 \mathrm{mg} / \mathrm{ml}$ for FOC in resin extract and $121.91 \mathrm{mg} / \mathrm{ml}$ for M. fructigena to $364.59 \mathrm{mg} / \mathrm{ml} \mathrm{for} \mathrm{FOC} \mathrm{in}$ leaf extract. As a result, the resin extract against the test organisms was found to be more effective than the leaf extract.
\end{abstract}

Keywords: Antifungal effects, Plant extracts, Liquidambar orientalis, Fusarium oxysporum f.sp. cucumerinum, Monilinia fructigena

*Abdurrahman ONARAN; abdonaran@ hotmail.com; Tel: (0356) 25216 16; orcid.org/0000-0003-0665-8535 


\section{Giriş}

Dünya'da ve ülkemizde, sebze ve meyvelerde ekonomik anlamda ürün kayıplarına neden olan pek çok hastalık etmeni bulunmaktadır. $\mathrm{Bu}$ çalışmada kullanılan fungal hastalık etmenlerinden, Fusarium solgunluk hastalığ Dünya'nın birçok yerinde hıyarda Fusarium oxysporum f. sp. cucumerinum tarafindan ciddi ekonomik kayıplara neden olan bir patojendir. $\mathrm{Bu}$ patojen hıyar bitkisine özelleşmiştir (Ahn vd., 1997; Owen, 1955). Monilinia fructigena elmalarda mumyalaşma hastalığının etmeni olup, yumuşak ve sert çekirdekli meyve ağaçlarında meyvenin mumyalaşarak dalda asılı kalması şeklinde görülmektedir (Van vd., 2000).

Türkiye'de Aydın ve Muğla civarında (Köyceğiz) yetişen, bu bölgede günlük ağacı olarak bilinen Anadolu sığla ağacı, (Liquidambar orientalis var. orientalis Mill.) endemik bir ağaçtır. $\mathrm{Bu}$ ağaç türü, 20 metreye kadar boylanabilmekte ve görünüş olarak çınara benzemektedir. Ege ve Akdeniz Bölgelerinin doğal sınırı olan Dalaman çayı boyunca yayılım göstermektedir. Subtropikal iklim özellikleri görülen sıcak, nemli ve suyu bol yerlerde yetişen uzun ömürlü bir ağaçtır (Hill, 1952; Günal, 1994).

Bitkilerden elde edilen, bitkisel kaynaklı ürünlerin antifungal etkileri her geçen gün önem kazanmaktadır. $\mathrm{Bu}$ antifungal maddeler genellikle hiçbir yan etkisi olmayan, benzersiz özelikte bir avantaj sağlamaktadır. Günümüzde bitki patojenlerine karş1 kullanılan pestisitler yan etkileri sebebiyle çevre ve insan sağlığını olumsuz bir şekilde etkilemektedir. $\mathrm{Bu}$ nedenle, pestisit kullanımını en aza indirecek alternatif mücadele yöntemlerinin araştırılması önem arz etmektedir. Yapılan araştırmalar sonucunda bitkilerden elde edilen ekstraktların antifungal (Dülger ve Hacıoğlu, 2008; Erdoğan vd., 2016; Kalkışım, 2012; Şin vd., 2017), antibakteriyel (Basım vd., 2000; Baydar vd., 2004; Kalhora vd., 2014), nematisidal (Hatipoğlu ve Kaşkavalcı, 2007; Kaşkavalcı ve Civelek, 2009; Tan, 2011), herbisidal (Kordali vd., 2009; Y1lar vd., 2012; Özcan vd., 2013) ve insektisidal (Aslan vd., 2005; Gökçe vd., 2006; Karakoç vd., 2013) etkiye sahip olduğu bir çok araştırıcı tarafından belirlenmiştir. Sığla ağacından elde edilen bitki ekstraklarının antifungal etkinliğinin belirlenmesi üzerine oldukça kısıtlı sayıda araştırma bulunmaktadır (Lee vd., 2009; Onaran ve Bayan, 2016).

Bu çalışmada, ülkemiz florasında endemik olarak yetişen Liquidambar orientalis L. bitkisinden elde edilen reçine ve yaprak methanol ekstraktının, hiyar'da Fusarium oxysporum f.sp. cucumerinum (FOC) ve elma'da Monilinia fructigena bitki fungal patojenlerine karşı antifungal etkilerinin belirlenmesi amaçlanmıştır.

\section{Materyal ve Metot}

\subsection{Bitki Materyali}

Çalışmada kullanılan Liquidambar orientalis Mill. bitkisine ait yaprak kısımları 2016 yılında gelişme dönemlerine göre Muğla İli'nden toplanmıştır. Toplanan bitki kısmı steril saf suyla yıkanmış ve oda sıcaklığında gölgede kurutulmuş, daha sonra her bitki kısmı öğütücüden geçirilerek küçük parçalara ayrılması sağlanmıştır. Sığla bitkisine ait reçine kısmı ise Muğla İli'nin Köyceğiz İlçesi'nden köylülerden temin edilmiştir. Reçine elde etmek için bahar aylarında ağacın gövdesine çizikler çizilerek, temmuz ayından itibaren gövde üzerinde biriken salgı ve kabuklar özel bıçaklar ile kazınarak toplanmış ve bu salgı ve kabuklar sıcak su ile kaynatıldıktan sonra özel preslerde sıkılarak sığla reçinesi elde edilmiştir.

\subsection{Bitki Ekstraktı}

Ögütülmüş bitki materyalinden 100 gr tartılarak 1L cam kaplara konulmuş ve bitki örneğinin üzerini kapatacak kadar organik çözücü methanol (gr/mL) ilave edilmiştir. Çözelti, 72 saat oda sicaklığında $\left(25 \pm 2^{\circ} \mathrm{C}\right)$ inkubatörlü orbital çalkalayıcıda (Lab. corporation Group, Model-SI300) 120 rpm de karıştırılmış ve ekstraktlar kaba filtre kağıdından geçirilerek, organik çözücü ratory evaporator (Heildolph Group, Model-HeiVap Presicion) ile $40^{\circ} \mathrm{C}$ 'de buharlaştırılarak uzaklaştırılmıştır. Elde edilen kuru ekstrakt ve reçine \%50 sulu aseton ile çözülmüştür (Kalkışım, 2012).

\subsection{Bitki Patojenleri}

Çalışmada, Gaziosmanpaşa Üniversitesi, Ziraat Fakültesi, Bitki Koruma Bölümü, Fitopatoloji laboratuvarı stok kültürlerinde yer alan ve hyyardan izole edilen Fusarium oxysporum f.sp. cucumerinum ile elmadan izole edilen Monilinia fructigena bitki patojeni funguslar kullanılmıştır. Fungus kültürleri, $20 \mathrm{ml}$ potato dextrose agar (PDA) içeren $90 \mathrm{~mm}$ petri kaplarında $25 \pm 2^{\circ} \mathrm{C}$ 'de 7 gün geliştirildikten sonra çalışmada kullanılmıştır.

\subsection{Besi Ortamı}

Patojen fungusların çoğaltılmasında ve antifungal etkinin saptanmasinda standart besiyeri olan 
Patates Dekstroz Agar (PDA; Merck) (40 g PDA, $1000 \mathrm{ml}$ saf su) besiyeri kullanılmıştır.

\subsection{Antifungal Etki Çalış̧maları}

Sığla ağacı yaprak ekstraktının ve reçinesinin antifungal etkisini belirlemek amaciyla agar plate metodu uygulanmıştır (Nwosu ve Okafor, 1995). Otoklavda $121^{\circ} \mathrm{C}$ 'de 20 dakika sterilize edilen ve $40^{\circ} \mathrm{C}^{\prime}$ ye kadar soğutulan PDA besi yerine sığla ağacının yaprak ekstraktı ve reçinenin son konsantrasyonlar1 0 (negatif kontrol), 5, 10 ve 20 $\mathrm{mg} / \mathrm{ml}$ olacak şekilde dozlar ilave edilmiştir. Sterilize edilen karışımdan her bir steril petriye (6 $\mathrm{cm}$ çap) $10 \mathrm{ml}$ dökülmüştür. Petriler oda şartlarında bir gece bekletildikten sonra, daha önceden PDA besi yerinde geliştirilen yedi günlük patojen kültürlerinin büyümenin devam ettiği uç kısımlarından $5 \mathrm{~mm}$ çaplı mantar delici ile diskler alınarak PDA besi ortamının ortasına fungusun bulunduğu besin ortamına temas edecek şekilde birer adet disk aktarılarak $23 \pm 2^{\circ} \mathrm{C}^{\prime}$ de 7 gün boyunca inkübasyona birakılmıştır. Fungal gelişimler her günün sonunda kayıt edilmiş ve 7 gün boyunca devam edilmiştir (Onaran ve Yılar, 2012). Koloni çapının ölçümü fungus koloni çapının birbirine dik ayrı yönde ölçülmesi şeklinde yapılmıştır (Benjilali vd., 1984). Pozitif kontrol olarak standart bir fungusit olan thiram \%80 ticari firmanın önerdiği dozda kullanılmıştır. Negatif kontrol olarak ise \%50 aseton kullanılmıştır. Deneme 4 tekerrürlü ve 2 tekrarlamalı olarak yürütülmüştür. Elde edilen sonuçlara göre yüzde miselyum gelişim engellemesi (MGE) ise aşağıdaki formül yardımıyla hesaplanmıştır (Pandey vd., 1982).

$M G E=\frac{d c-d t}{d c} \times 100$

MGE (\%): Miselyum gelişim engellemesi

dc: Kontroldeki miselyum gelişmesi

dt: Uygulamadaki miselyum gelişmesi

\section{6. İstatistiksel Analiz}

Çalışma sonucunda elde edilen veriler, SSPS istatistik paket programı kullanılarak varyans analizine tabi tutulmuş, ortalamalar arasındaki farklar DUNCAN testi ile belirlenmiştir. Lethal dozlar $\left(\mathrm{LD}_{50-90}\right)$ Polo 1.0 programı kullanılarak belirlenmiştir.

\section{Bulgular ve Tartışma}

Çalışmada, sığla bitkisinin reçine ve yaprak methanol ekstaktlarının önemli bitki patojenlerinden $F$. oxysporum f.sp. cucumerinum (FOC) ve $M$. fructigena'ya karş1 antifungal etkileri araştırılmıştır. Bitki patojenlerinin sı̆̆la ağacının yaprak ve reçine ekstraktlarına karşı göstermiş oldukları miselyum gelişmeleri Şekil 1 ve 2'de verilmiştir. Sığla ağacının yaprak ve reçine ekstraktları değişen oranlarda istatistiki olarak $(\mathrm{P}=0.05)$ antifungal etki göstermiştir.

L. orientalis'in yaprak ekstraktının üç dozunda da bitki patojenlerinin gelişimini engellediği belirlenirken, her patojen için antifungal etki değerleri farklı bulunmuştur. Her iki patojen için en yüksek miselyum gelişimi $5 \mathrm{mg} / \mathrm{ml}$ dozunda saptanırken, en düşük miselyum gelişimi 20 $\mathrm{mg} / \mathrm{ml}$ dozunda saptanmıştır. $M$. fructigena FOC'a göre yaprak ekstraktından daha fazla etkilenmiştir. Yaprak ekstraktının dozu arttıkça antifungal etkisi de artmıştır. Her iki patojen grubu içinde pozitif kontrolde miselyum gelişmesi olmamıştır (Şekil 1).

L. orientalis'in reçine ekstraktının üç dozu benzer şekilde bitki patojenlerinin gelişimini engellerken, her patojen için antifungal etki değerleri de farklı bulunmuştur. Yine benzer şekilde her iki patojen için en yüksek miselyum gelişimi $5 \mathrm{mg} / \mathrm{ml}$ dozunda saptanırken, en düşük miselyum gelişimi $20 \mathrm{mg} / \mathrm{ml}$ dozunda saptanmış ve $M$. fructigenia'da miselyum gelişmesi olmamıştır. Reçine ekstraktında M. fructigenia FOC'a göre daha fazla etkilenmiştir. Yaprak ekstraktında olduğu gibi doz arttıkça antifungal etkide artmıştır. Test mikroorganizmaları pozitif kontrolde gelişme göstermemiştir. Bitki patojenlerine karşı reçine ekstraktı yaprak ekstraktından daha fazla etkili bulunmuştur (Şekil 2).

Test edilen mikroorganizmalara karşı yaprak ve reçine ekstraktlarının yüzde miselyum gelişim engellemeleri (MGE) Tablo 1'de verilmiştir. Tablo 1 incelendiğinde, doz artışına bağlı olarak miselyum gelişiminin tamamen durduğu, hatta $\% 100$ engellemenin olduğu belirlenmiştir. En yüksek yüzde miselyum gelişim oranı reçine ekstraktında $10 \mathrm{mg} / \mathrm{ml}$ ve $20 \mathrm{mg} / \mathrm{ml}$ dozlarında $M$. fructigena (\%100 ve \%97) hastalık etmenine karş1 gözlenmiştir. Yaprak ekstraktında ise en yüksek etki $M$. fructigena' ya karş1 $20 \mathrm{mg} / \mathrm{ml}$ dozunda \%66 oranında gerçekleşmiştir. Her iki patojene karşı yaprak ekstraktının miselyum gelişim engelleme oranı reçine ekstraktına göre daha düşük saptanmıştır. 


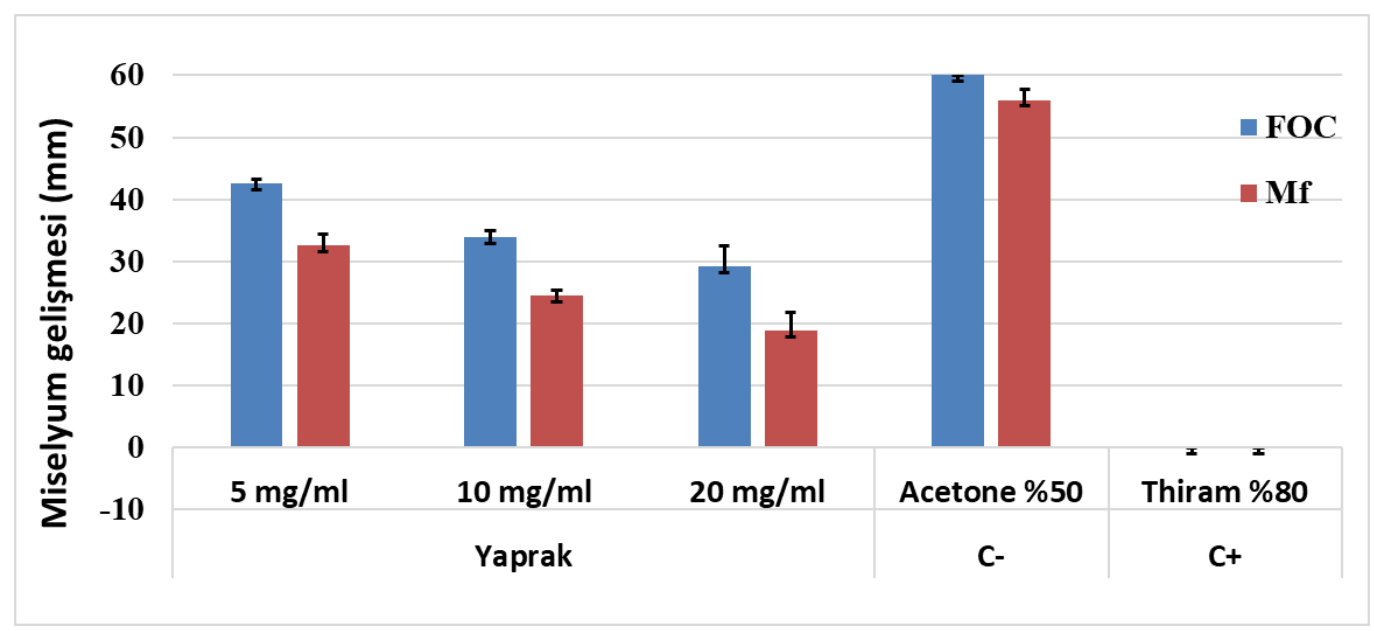

Şekil 1. L. orientalis yaprak ekstraktının test mikroorganizmalarının miselyum gelişimi üzerine etkileri. FOC: Fusarium oxysporum f. sp. cucumerinum, Mf: Monilinia fructigena, C-: Negatif kontrol, C+: Pozitif kontrol

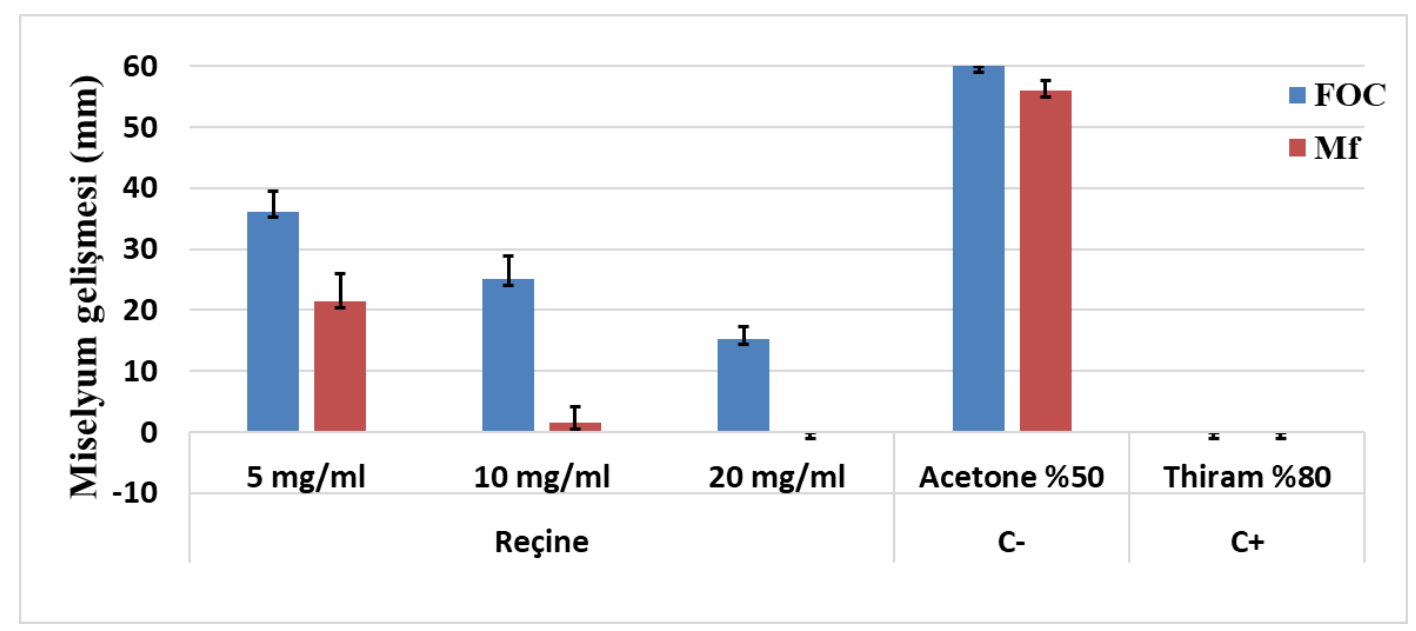

Şekil 2. L. orientalis reçine ekstraktının test mikroorganizmalarının miselyum gelişimi üzerine etkileri. FOC: Fusarium oxysporum f. sp. cucumerinum, Mf: Monilinia fructigena, C-: Negatif kontrol, C+: Pozitif kontrol

Tablo 1. Test mikroorganizmalarına karşı $L$. orientalis ekstraktlarının miselyum gelișim engellemesi (\%).

\begin{tabular}{|c|c|c|c|}
\hline Bitki kısımları & Dozlar (mg/ml) & *FOC & $* \mathbf{M f}$ \\
\hline \multirow{3}{*}{ Reçine } & 5 & 40 & 62 \\
\hline & 10 & 58 & 97 \\
\hline & 20 & 74 & 100 \\
\hline \multirow{3}{*}{ Yaprak } & 5 & 29 & 42 \\
\hline & 10 & 43 & 56 \\
\hline & 20 & 51 & 66 \\
\hline $\mathrm{C}-$ & Aseton $\% 50$ & 0 & 0 \\
\hline $\mathrm{C}+$ & Thiram \%80 & 100 & 100 \\
\hline
\end{tabular}

Test edilen mikroorganizmalara karşı kullanılan sığla ağacının ekstraktlarının $\mathrm{LD}_{50} \quad$ (Test organizmalarının \%50'sini öldüren doz) ve $\mathrm{LD}_{90}$ (Test organizmalarının \%90'nını öldüren doz) değerleri hesaplanmıştır (Tablo 2). Elde edilen sonuçlara göre; reçine ekstraktında $\mathrm{LD}_{50}$ değeri FOC' da $7.32 \mathrm{mg} / \mathrm{ml}$, M. fructigena' da $4.42 \mathrm{mg} / \mathrm{ml}$ olarak belirlenirken, yaprak ekstraktında bu oran $16.98 \mathrm{mg} / \mathrm{ml}$ ve $7.66 \mathrm{mg} / \mathrm{ml}$ olarak belirlenmiştir.

Reçine ekstraktında $\mathrm{LD}_{90}$ değeri $\mathrm{FOC}$ 'da 51.48 $\mathrm{mg} / \mathrm{ml}, \quad$ M. fructigena' da $7.68 \mathrm{mg} / \mathrm{ml}$ olarak saptanırken, yaprak ekstraktında bu oran 364.59 $\mathrm{mg} / \mathrm{ml}$ ve $121.91 \mathrm{mg} / \mathrm{ml}$ olarak saptanmıştır. $L$. orientalis'in ekstraktlarına en duyarlı hastalık etmeninin $M$. frugtigena olduğu belirlenmiştir. 
Tablo 2. Test mikroorganizmalarına karşı $L$. orientalis'in ekstraktlarının lethal doz değerleri $(\mathrm{mg} / \mathrm{ml})$

\begin{tabular}{|c|c|c|c|}
\hline \multicolumn{2}{|c|}{$\begin{array}{l}\text { Test } \\
\text { Mikroorganizmaları }\end{array}$} & $\begin{array}{l}\text { Reçine } \\
(\mathrm{mg} / \mathrm{ml})\end{array}$ & $\begin{array}{l}\text { Yaprak } \\
(\mathrm{mg} / \mathrm{ml})\end{array}$ \\
\hline \multirow{5}{*}{$* \mathbf{F O C}$} & $\mathbf{L D}_{50}$ & 7.32 & 16.98 \\
\hline & $\mathbf{L D}_{\mathbf{9 0}}$ & 51.48 & 364.59 \\
\hline & Slope & $1.513 \pm 0.230$ & $0.962 \pm 0.225$ \\
\hline & Heterojenite & 0.58 & 0.35 \\
\hline & Ki-Kare & 4.75 & 2.42 \\
\hline \multirow{5}{*}{$* \mathbf{M f}$} & $\mathbf{L D}_{\mathbf{5 0}}$ & 4.42 & 7.66 \\
\hline & $\mathbf{L D}_{90}$ & 7.68 & 121.91 \\
\hline & Slope & $5.346 \pm 0.699$ & $1.066 \pm 0.232$ \\
\hline & Heterojenite & 1.99 & 0.31 \\
\hline & Ki-Kare & 13.96 & 2.17 \\
\hline
\end{tabular}

Daha önce yapılan bir başka çalışmada, $L$. orientalis'in reçine ekstraktının 13 adet ekonomik önemi olan bitki bakteri hastalığına karşı \%1, 2.5, 5,10 ve 20 konsantrasyonlarında antibakteriyel özelliği araştırılmış, en yüksek antibakteriyel etki \%20'lik konsatrasyonda bulunmuştur. Uygulamanın hem in vitro hem de in vivo çalışmalarda Clavibacter michiganensis subsp. michiganensis, Pseudomonas syringae pv. tomato ve Xanthomonas axonopodis pv. Vesicatoria'nın gelişimini tamamen engellediği bildirilmiştir (Basım ve Basım, 2013). Bir diğer çalışmada, aralarında $L$. orientalis' de bulunduğu ticari olarak satılan 40 adet bitki yağının, Phytophthora cactorum, Cryphonectria parasitica ve Fusarium circinatum bitki patojenlerine karşı antifungal etkisi belirlenmiş, en yüksek antifungal etkinin $L$. orientalis'in reçine ekstraktında Phytophthora cactorum'a karşı gerçekleştiği tespit edilmiş ve ekstraktın güçlü şekilde spor ve miselyum gelişimini engellediği vurgulanmıştır (Lee vd, 2009). Onaran ve Bayan (2016)'da L. orientalis' in yaprak ve reçine ekstraktlarının antifungal etkinliğini bir başka önemli bitki fungal hastalık etmenlerinden olan Fusarium oxysporum $f$. $s p$. lycopersici, Alternaria solani, Botrytis cinerea, Rhizoctonia solani, ve Sclerotinia sclerotiorum'a karşı araştırmışlardır. Yapılan literatür taramalarında, fungal hastalık etmenlerinden Fusarium oxysporum f.sp. cucumerinum ve Monilinia fructigena karş1 $L$. orientalis'in etkinliğinin belirlendiği bir çalışmaya rastlanmamıştır. Çalışma sonucunda sığla ağacından elde edilen reçine yağından ümitvar sonuçlar elde edilmiştir. Ayrıca, çeşitli araştırıcılar tarafindan $L$. orientalis'den elde edilen yaprak ve reçine ekstraktlarının antibakteriyel (Sağdıç vd., 2005), nematicidal (Kim vd., 2008) ve insektisidal (Kanat ve Alma, 2004) etkinliklerinin olduğu da belirlenmiştir.

\section{Sonuç}

Geçmişten günümüze kadar, bitkilerin bünyelerinde bulunan antifungal maddelerin belirlenerek kullanımının artırılmasına yönelik birçok araştırma yapılmıştır. $\mathrm{Bu}$ araştırmalar sonucunda, yeni doğal antifungal maddeler bulunmuş ve bulunmaya devam edilmektedir. Doğal antifungal maddelerin kullanımı sonucunda, bitki hastalıkların mücadelesinde kullanılan kimyasalların daha az kullanımına olanak sağlamıştır.

Yapılan bu çalışmada, L. orientalis ekstraktları $F$. oxysporum f.sp. cucumerinum ve $M$. fructigena' a ait izolatlara in vitro şartlarda etkili bulunmuştur. Bu etkinin farklı sıcaklık ve nem değerlerine sahip olan arazi koşullarında değişiklik gösterebileceği muhtemeldir. Gelecekte bu hastalik etmenlerine karşı etkili olan bu ekstraktları da içine alacak şekilde çalışmaların yapılması önemlidir. $L$. orientalis ekstraktlarının madde tayin çalışmalarına öncülük edeceği ve bitki patojenlerinin kontrolünde kullanılan pestisitlerin yerini alabilecek alternatif mücadele yöntemlerinin geliştirilmesi açısından olanak sağlayacağı ön görülmektedir.

\section{Kaynaklar}

Ahn I.P, Chung H.S., ve Lee Y.H., 1997. Vegetative compat-ibility groups and pathogenicity among isolates of Fusarium oxysporum f. sp. cucumerinum. Plant Disease, 82, 244-246.

Aslan, İ. Çalmaşur, Ö., Şahin, F. ve Çağlar, Ö., 2005. Insecticidal effects of essential plant oils against Ephestia kuehniella (Zell.), Lasioderma serricorne (F.) and Sitophilus granarius (L.). Journal of Plant Diseases and Protection, 112, 257-267.

Basim, E. ve Basim, H., 2013. Antibacterial activity of Turkish endemic sığla (Liquidambar orientalis Mill. var. orientalis) storax against agricultural plant pathogenic bacteria and its use as a seed protectant. Journal of Food, Agriculture \& Environment, 11(3\&4), 2447-2450.

Basim, H., Yeğen, O. ve Zeller, W., 2000. Antibacterial effect of essential oil of $T$. Spicata L. var. spicata on some plant pathogenic bacteria. Zeitschrift fur Pflanzenkrankheiten und Pflanzenschutz, 107, 279-284. 
Baydar, H., Sağdıç, O., Ozkan, G. ve Karadoğan, T., 2004. Antibacterial activity and composition of essential oils from Origanum, Thymbra and Satureja species with commercial importance in Turkey. Food Control, 15, 169-172.

Benjilali, B., Tantadui-Elaraki, A., Ayadi, A. ve Ihlal, M., 1984. Method to Study Antimicrobial Effects of Essential Oils: Application to the Antifungal Activity of Six Moroccan Essences. Journal of Food Protection, 47, 748-752.

Dülger, B. ve Hacioğlu, N., 2008. Antifungal Activity of Endemic Salvia tigrina in Turkey. Tropical Journal of Pharmaceutical Research, 7(3), 1051-1054.

Erdogan, O., Celik, A. ve Zeybek, A., 2016. In Vitro Antifungal Activity of Mint, Thyme, Lavender Extracts and Essential Oils on Verticillium dahliae Kleb. Fresenius Environmental Bulletin, 25(11), 4856-4862.

Gökçe, A., Whalon, M.E., Çam, H., Yanar, Y., Demiştaş, İ. ve Gören, N., 2006. Plant extract contact toxicities to various developmental stages of Colorado potato beetles (Coleoptera: Chrysomelidae). Annals of applied Biology, 149, 197-202.

Günal, N., 1994. Liquidambar orientalis (Anadolu Siğla Ağac1)'in Güneybatı Anadolu'daki Yayılışında Relief -İklim İlişkileri. Türk Coğrafya Dergisi, 29, 175- 190.

Hatipoğlu, A. ve Kaşkavalcı, G., 2007. Kök-ur nematodlar1 [Meloidogyne incognita (Kofoid\&White) Chitwood]'na karş1 savaşta bazı bitki kısımlarının etkileri üzerine araştırmalar. Türkiye Entomoloji Dergisi, 31 (2), 139-151.

Hill, A. F., 1952. Economic Botany: A Textbook of Useful Plants and Products. Vol. 2. New York: McGraw Hill; 560 p.

Kalhoro, M. A., Farheen, S. ve Aqsa, N.U., 2014. The Antimicrobial activity of ethanol extract of Vitex agnus castus. American International Journal of Contemporary Research, 1(1), 47-50.

Kalkışım, Ö., 2012. In vitro antifungal evaluation of various plant extracts against walnut anthracnose (Gnomonia leptostyla (Fr.) Ces et de Not.). Journal of Food, Agriculture \& Environment, 10(3\&4), 309-313.

Kanat, M. ve Alma, M.H., 2004. Insecticidal effects of essential oils from various plants against larvae of pine processionary moth (Thaumetopoea pityocampa Schiff) (Lepidoptera: Thaumetopoeidae). Pest management science, 60(2), 173-177.

Karakoç, Ö. C., Tüfekçi, A.R., Demirtaş, İ. ve İpek, A., 2013. Salvia tchihatcheffii ve Salvia cryptantha Uçucu Yağlarının ve Ekstraktlarının İki Önemli Depo Zararlıs1 Üzerindeki İnsektisidal Aktiviteleri. Tarım Bilimleri Araştırma Dergisi, 6 (1), 155-158.

Kaşkavalcı, G. ve Civelek, H.S., 2009. Effects of Two Plant Extracts on the Damage of Meloidogyne incognita in Tomato Plants. Ekoloji, 18 (72), 16-22.

Kim, J., Seo, S.M., Lee, S. G., Shin, S. C. ve Park, I.K., 2008. Nematicidal activity of plant essential oils and components from coriander (Coriandrum sativum), oriental sweetgum (Liquidambar orientalis), and valerian (Valeriana wallichii) essential oils against pine wood nematode (Bursaphelenchus xylophilus). Journal of Agricultural and Food Chemistry, 56(16), 7316-7320.

Kordali, Ş., Çakır, A., Akcin, T.A., Mete, E., Akcin, A., Aydın, T. ve Kılıç, H., 2009. Antifungal and herbicidal properties of essential oils and n-hexane extracts of Achillea gypsicola Hub-Mor. and Achillea biebersteinii Afan. (Asteraceae). Industrial Crops and Products, 29, 562-570.

Lee, Y. S., Kim, J., Lee, S. G., Oh, E., Shin, S. C. ve Park, I. K., 2009. Effects of plant essential oils and components from Oriental sweetgum (Liquidambar orientalis) on growth and morphogenesis of three phytopathogenic fungi. Pesticide Biochemistry and Physiology, 93(3), 138143.

Nwosu, M. O. ve Okafor, J. 1., 1995. Preliminary studies of the antifungal activites of some medicinal plants against Basidiobolus and some other pathogenic fungi. Mycoses, 38, 191-195. 
Onaran, A., Bayan, Y. 2016. Antifungal Activity of Liquidambar orientalis L., and Myrtus communis L. Against some Plant Pathogenic Fungi. Scientific papers-series a-agronomy, 59, 360-364.

Onaran, A., ve Y1lar, M., 2012. Antifungal activity of Trachystemon orientalis L. aqueous extracts against plant pathogens. Journal of Food, Agriculture \& Environment, 10(3\&4), 287-291.

Owen, J. H., 1955. Fusarium wilt of cucumber. Phytopathology, 45, 435-439.

Özcan, S., Yılar, M., Belgüzar, S. ve Önen, H., 2013.Teucrium polium L. Uçucu Yağının Herbisidal ve Antifungal Etkileri ile Kimyasal İçeriğinin Belirlenmesi. Gaziosmanpaşa Bilimsel Araştırma Dergisi, 5, 94-103.

Pandey, D.K., Tripathi, N.N., Tripathi, R.D. ve Dixit, S.N., 1982. Fungitoxic and phytotoxic properties of essential oil of Hyptis suaveolens. Zeitschrift für Pflanzenkrankheiten und Pflanzenschutz, 89(6), 344-349.

Sağdıç, O., Özkan, G., Özcan, M. ve Özçelik, S., 2005. A study on inhibitory effects of sığla tree (Liquidambar orientalis Mill. var. orientalis) storax against several bacteria. Phytotherapy Research, 19(6), 549-551.

Şin, Bahadır, Kadıŏlu, İ. ve Onaran, A., 2017. Parazit bitkilerden (Orobanche ramosa L., Cuscuta campestris Yunck. ve Viscum album L.) elde edilen ekstratların bazı bitki patojeni funguslara karşı antifungal etkileri. Turkish Journal of Weed Science, 20(1), 61-69.

Tan, A.N., 2011. Nematisit Etkili Bitkiler ve Bitki Ekstraktları. Ege Üniversitesi Ziraat Fakültesi Dergisi, 48(2), 165-173.

Van Leeuwen, G.C.M., Stein, A., Holb, I. ve Jeger, M.J., 2000. Yield loss in apple caused by Monilinia fructigena (Aderh. \& Ruhl.) Honey, and spatio-temporal dynamics of disease development. European Journal of Plant Pathology, 106(6), 519-528.

Yılar, M., Bayan, Y., Özcan, S., Akşit, H. ve Kadıŏlu, İ., 2012. Artemisia scoparia Waldst. et Kit. Uçucu Yağının Biyoherbisidal Etkisi. Gümüşhane Üniversitesi Fen Bilimleri Enstitüsü Dergisi, 2(1), 11-20. 